\section{Prostate cancer mortality trends in Argentina 1986-2006: an age-period-cohort and joinpoint analysis}

\author{
Tendencias en la mortalidad por cáncer de \\ próstata en Argentina 1986-2006: análisis \\ joinpoint y de edad-período-cohorte
}

Camila Niclis 1,2

Sonia A. Pou 1,3

Rubén H. Bengió 1

Alberto R. Osella 4

María del Pilar Díaz 1
1 Facultad de Ciencias Médicas, Universidad Nacional de Córdoba, Córdoba, Argentina.

2 Agencia Nacional de Promoción Científica y Tecnológica, Argentina.

3 Consejo Nacional de Investigaciones Científicas y

Técnicas, Argentina.

${ }^{4}$ Laboratorio di

Epidemiologia e Biostatistica, IRCCS "Saverio de Bellis", Bari, Italia.

Correspondence

M. P. Díaz

Escuela de Nutrición,

Facultad de Ciencias

Médicas, Universidad

Nacional de Córdoba.

Enrique Barros esq.

Enfermera Gordillo, Ciudad Universitaria, Córdoba 5000, Argentina.

pdiaz@fcm.unc.edu.ar

\section{Abstract}

The aim of this study was to give an overview of the magnitude, variation by age and time trends in the rates of prostate cancer mortality in Córdoba province and in Argentina as a whole from 1986 to 2006. Mortality data were provided by the Córdoba Ministry of Health and the World Health Organization cancer mortality database. Prostate cancer mortality time trends were analyzed using joinpoint analysis and age-periodcohort models. In Argentina prostate cancer age-standardized mortality rates rose by $1 \%$ and 3.4\% per year from 1986 to 1992 and from 1992 to 1998 respectively. There was a decreasing trend (-1.6\%) for Argentina from 1998 and Córdoba (-1.9\%) from 1995. Age-period-cohort models for the country and the province showed a strong age effect. In the country there was an increased risk in the 1996-2000 period, whereas there was decreased risk for birth cohorts since 1946, principally in Córdoba. A decreasing trend in prostate cancer mortality was found in Córdoba as well as in Argentina, which might be attributed to the improvement in treatment in this country.

Prostatic Neoplasms; Mortality Rate; Men's Health

\section{Introduction}

Cancer is a leading cause of death worldwide. Deaths from cancer are projected to continue rising and in some countries it has already become the principal cause of death ${ }^{1}$. More than $70 \%$ of all cancer deaths occurred in middle- to low -income countries in 20052.

Prostate cancer is the second most common cancer in men ${ }^{3}$. It is, in turn, the third most common cause of cancer death in men in Argentina 4. Average survival for prostate cancer is relatively high, although it is markedly higher in high-income countries. The five-year survival rate is approximately 60 per cent overall: 76 per cent in high-income countries, compared with 45 percent in middle- to low-income countries. This cancer accounts for around six per cent of all cancer incidence (nearly 12 per cent in men) bur around three per cent of all cancer deaths (almost six per cent in men; all sites except for non-melanoma skin) 5 .

The risk of prostate cancer increases with age and is diagnosed in very few people aged 50 years or younger 6 . After this age, incidence and mortality rates increase almost exponentially. The increase in cancer incidence throughout life is mainly due to an accumulation of risks, combined with a trend in loss of effectiveness in cellular repair mechanisms with ageing 7 . The dramatic increase of prostate cancer incidence between 1988 and 1992 in the USA was largely due to the 
increased availability of screening for prostatespecific antigen in men without symptoms of the disease 5 . Rates were already increasing before the availability of prostate-specific antigen testing, and have continued to increase in middleincome countries where the screening is still not widely available 5 .

In Argentina, prostate-specific antigen testing was introduced in around the mid-1980s, and since the mid-1990s the Argentinean Urology Society has proposed a systematic screening in adult men older than 50 years through annual rectal examinations and prostate-specific antigen testing ${ }^{8}$. Nevertheless, it is difficult to quantify the impact of the screening effect in prostate incidence trends in our country because the number of new cancer cases diagnosed every year in Argentina is unknown since there is no national registry. As such, incidence rates throughout the country and for different types of cancer are not known, except for some small size studies of incidence in some provinces. The Córdoba Cancer Registry, which began in 2003, is the largest province population-based registry. According to this source, the 2004 prostate age standardized mortality rate was $13.62 \times 10^{-5}$ inhabitants ${ }^{9}$, but the temporal pattern is obviously not yet available. However, in the specific case of prostate cancer, mortality rates are considered a useful and unbiased indicator for descriptive purposes as incidence rates are usually inflated by a large proportion of preclinical diagnoses due to prostate-specific antigen 10 .

Recently published data for prostate-cancer mortality trends in Argentina (from 1980 to 2001), showed that rates had raised $2.6 \%$ annually since 1984 followed by a decreasing trend from 1998 whereas Córdoba province rates have been decreasing since 1980 (at about 2\% per year) 11 .

Although it is known that interpreting temporal trends in prostate cancer incidence and mortality is not simple 12 , even less so in countries where data about certain factors are not readily available, in this paper we analyze prostate mortality data. The aim of our study is to give an overview of the magnitude and the time trends in the rates of prostate cancer mortality identifying the effect of age, period and cohort in Córdoba province and in Argentina as a whole from 1986 to 2006.

\section{Methods}

\section{Data sources}

Córdoba is a central Argentinean province with a population of about 3,100,000 inhabitants (about
9\% of the Argentinean population). Overall $80 \%$ of the population of Córdoba province is urban with seven counties with 100,000 to 200,000 inhabitant and only two counties with fewer than 5,000 inhabitants in the northern part of the province, which has the lowest population density. Rural zones cover almost all of the South of Córdoba province.

Prostate cancer (C61) mortality statistics for Córdoba (1986-2006) and Argentina (1986-2005) were obtained, respectively, from the Córdoba Ministry of Health (Department of Statistics) and from the International Agency for Research on Cancer at the World Health Organization (IARCWHO. Cancer Mondial. http://www.dep.iarc.fr/, accessed on 20/Feb/2009).

During the calendar period considered, different revisions of the International Classification of Diseases (ICD) were used. Classification of cancer deaths was recoded for all calendar periods according to the tenth revision of the ICD 13 .

\section{Statistical analysis}

Prostate cancer age standardized mortality rates were estimated on the basis of World Standard population by the direct method 14 for Córdoba province and Argentina, and for each five year age group (35-, 40-, 45-, 50-, 55-, 60-, 65-, 70-, 75and 80 or older) and expressed as ASMRx10-5.

To identify changes in trends, joinpoint regression analysis was performed. The aim of this analysis is to identify possible points where a significant change in the linear slope of the trend (in a log scale) is detected over the study period. In joinpoint analysis the best fitting points, called joinpoints, are chosen where the rate changes significantly (the k-joinpoint model with the minimum value of Bayesian Information Criterion was selected). Each significant point that indicates a change in the slope (if any) is retained in the final model. To describe linear trends by period, the estimated annual percentage change and $95 \%$ confidence interval $(95 \% \mathrm{CI})$ is then computed for each of those trends by fitting a regression line to the natural logarithm of the rates using the calendar year as a regressor variable 15. Joinpoint software (Jointpoint Regression program. National Cancer Institute. http://srab.cancer.gov/ joinpoint/) was used to perform this analysis.

An age-period-cohort model was then fitted to the data. Data were tabulated into 4 five-year periods (1986-1990 to 2001-2005) of death (in the case of Córdoba, the last period covered six years, 2001-2006) and 11 five-year overlapping 10-year birth cohorts, identified by central year of birth from 1906 to 1986. The effect of age, period of death and birth cohort covariates on mortality 
rates were estimated using a Poisson regression model. This model assumes that the number of deaths is a Poisson random variable with expectation parameter depending on the number of person-years and the explanatory variables 16 .

Following biological plausibility criteria, age at death and cohort of birth were chosen as major and secondary time scale respectively. Poisson models were fitted sequentially. First an agecohort model was fitted by omitting an explicit intercept and choosing a suitable reference for cohort of birth (central year 1936 cohort was chosen as the reference cohort). In this way, the age at death effect will be the log incidence mortality rates (IR) for the reference cohort and the cohort effect will be log relative risks (RR). The log of the fitted values from this model was then used as an offset variable in a model with period effect. Thus, the estimates are the age-cohort marginal and period effects, conditional on the estimates from the age-cohort model and will usually be close to maximum likelihood estimates 17 .

Data management, direct standardization of rates and Poisson regression analysis were performed using Stata software, version 10.1 (Stata Corp, College Station, USA).

\section{Results}

Table 1 shows overall and age-specific age standardized mortality rates, estimated annual percentage change $(95 \% \mathrm{CI})$ and the most suitable models with estimated joinpoints for prostate cancer from 1986 to 2006 in Córdoba province and Argentina. From 1986 through 2006, around 6,000 people died due to prostate cancer in Córdoba province.

During the study period, age-standardized mortality rates (overall) for prostate cancer increased from 14.8 to 15.9 in Córdoba province and from 12.6 to 15.5 per $10^{-5}$ person-years in Argentina, but in these 20 years, tendencies have not followed a linear pattern. Overall, Argentina showed an increase (estimated annual percentage change $=1.0 \%$ from 1986 to 1992 and 3.4 from 1992 to 1998) and then a decline (estimated annual percentage change $=-1.6 \%$ ) in mortality from 1998 to 2005; Córdoba province also exhibited a decline in the last decade studied (estimated annual percentage change $=-1.9 \%$ from 1995 to 2006). Prostate cancer age standardized mortality rates for Córdoba province did not show significant changes throughout the study period when different age groups were considered, whereas Argentina showed changing patterns by age-group. In fact, prostate cancer age standardized mortality rates increased (estimated annual percentage change $=1.3 \%$ ) from 1986 to 1996 for men aged 55-64 and declined (estimated annual percentage change $=-1.5 \%$ ) from 1996 to 2005 . At age 65-74, age-standardized mortality rates increased (estimated annual percentage change = 3.6\%) from 1992 to 1998 and declined (estimated annual percentage change $=-2.1 \%$ ) thereafter. There was a steady age-standardized increase in mortality rates at age 75 or older from 1986 to 1994 (estimated annual percentage change = $1.8 \%$ ) and from 1994 to 1998 (estimated annual percentage change $=4.4 \%$ ).

Age-period-cohort models showed an estimated incidence mortality rate ranging from less than 1 at age $35-39$ to about 800 or 600 at age 80 or older per 10-5 person-years for Córdoba province and Argentina respectively, evidencing an exponential trend (Figure 1).

No period effect was evident for Córdoba province whereas Argentina showed a decreased $\mathrm{RR}$ in 1991-1995 (RR = 0.97; 95\%CI: 0.96-0.99) and 2001-2005 (RR = 0.97; 95\%CI: 0.96-0.99) with an increased RR in 1996-2000 (RR = 1.04; 95\%CI: 1.02-1.05). The cohort effect in Córdoba province and Argentina showed a decreasing trend toward the younger cohorts, with a significantly lower risk of dying from prostate cancer in men born in 1951 (RR = 0.50; 95\%CI: 0.28-0.89) in Córdoba province, while Argentina showed an increased risk $(\mathrm{RR}=1.10 ; 95 \% \mathrm{CI}$ : 1.01-1.21) for the 1946 central year birth cohort followed by a decreasing trend (Figure 1).

\section{Discussion}

In this study, it has been shown that prostate cancer age standardized mortality rates had a decreasing trend both in Córdoba province from 1995 and across Argentina from 1998, but deaths from this tumor still represent $10.6 \%$ and $10.1 \%$ of deaths in men from this province and from Argentina respectively, due to malignancies. Moreover, the age-period-cohort model showed a strong age effect in the province and in the country; period effects were similar in magnitude but with different statistical significance and substantially different cohort effects in the two geographical settings.

Variations in cancer distribution by sex, age, and location may be explained by differences between countries regarding the prevalence of risk factors, public health policies in both primary and secondary prevention, differences in demographic compositions, environmental exposure, lifestyles, etc ${ }^{18}$. Overall, in developed countries, such as the USA, the United Kingdom 19 and Italy ${ }^{20}$, mortality from main cancers has shown 
Prostate cancer mortality trends (joinpoint analysis), by age group (1986-2006) in Córdoba province and Argentina.

\begin{tabular}{|c|c|c|c|c|c|c|c|c|}
\hline \multirow[t]{3}{*}{$\begin{array}{l}\text { Age group } \\
\text { (years)/Place }\end{array}$} & \multicolumn{2}{|c|}{$\begin{array}{l}\text { ASMR (per 10-5 } \\
\text { persons/years) }\end{array}$} & \multirow{3}{*}{$\begin{array}{c}\text { Period from } \\
1986 \\
\text { to first JP }\end{array}$} & \multirow[t]{3}{*}{$\begin{array}{c}\text { EAPC } \\
(95 \% \mathrm{Cl})\end{array}$} & \multirow{3}{*}{$\begin{array}{l}\text { Period from } \\
\text { first to } \\
\text { second JP (or } \\
2005 / 2006 \text { ) * }\end{array}$} & \multirow[t]{3}{*}{$\begin{array}{c}\text { EAPC } \\
(95 \% \mathrm{Cl})\end{array}$} & \multirow{3}{*}{$\begin{array}{l}\text { Period from } \\
\text { second JP to } \\
2005 / 2006\end{array}$} & \multirow[t]{3}{*}{$\begin{array}{c}\text { EAPC } \\
(95 \% \mathrm{Cl})\end{array}$} \\
\hline & 1986 & 2006 & & & & & & \\
\hline & & & & & & & & \\
\hline \multicolumn{9}{|l|}{$55-64$} \\
\hline Córdoba & 24.5 & 27.8 & $86-96$ & $1.6(-3.6 ; 7.1)$ & $96-06$ & $-3.6(-8.7 ; 1.8)$ & & \\
\hline Argentina & 20.4 & 20.2 & $86-96$ & $1.3 * \star(0.2 ; 2.5)$ & $96-05$ & $-1.5^{\star \star}(-2.9 ;-0.2)$ & & \\
\hline \multicolumn{9}{|l|}{$65-74$} \\
\hline Córdoba & 86.5 & 102.6 & $86-98$ & $0.9(-1.3 ; 3.2)$ & $98-01$ & $-6.6(-8.0 ; 10.0)$ & $01-06$ & $1.2(-6.5 ; 9.5)$ \\
\hline Argentina & 87.7 & 96.8 & $86-92$ & $0.0(-2.2 ; 2.3)$ & $92-98$ & $3.6 * \star(0.8 ; 6.5)$ & $98-05$ & $-2.1 * \star(-3.0 ;-0.5)$ \\
\hline \multicolumn{9}{|l|}{$\geq 75$} \\
\hline Córdoba & 387.6 & 423.2 & $86-92$ & $-1.8(-6.6 ; 3.2)$ & $92-95$ & $6.4(-19.3 ; 40.3)$ & $95-06$ & $-1.0(-2.6 ; 0.6)$ \\
\hline Argentina & 298.1 & 419.6 & $86-94$ & $1.8 * \star(0.9 ; 2.7)$ & $94-98$ & $4.4^{\star \star}(0.5 ; 8.4)$ & $98-05$ & $-0.5(-1.4 ; 0.5)$ \\
\hline \multicolumn{9}{|l|}{ All ages } \\
\hline Córdoba & 14.8 & 15.9 & $86-92$ & $-0.3(-4.1 ; 3.6)$ & $92-95$ & $4.0(-16.2 ; 8.2)$ & $95-06$ & $-1.9 * \star(-3.3 ;-0.4)$ \\
\hline Argentina & 12.6 & 15.5 & $86-92$ & $1.0 * \star(0.0 ; 2.0)$ & $92-98$ & $3.4^{\star \star}(2.2 ; 4.7)$ & $98-05$ & $-1.6 * \star(-2.3 ;-0.9)$ \\
\hline
\end{tabular}

ASMR: age standardized mortality rates; EAPC: estimated annual percentage changes; JP: joinpoint; $95 \% \mathrm{Cl}$ : $95 \%$ confidence interval.

* For the 55-64 group, the models with the best fit had 1 joinpoint. For the "all ages" group, the model with the best fit to Córdoba data had 1 joinpoint, but the model with two joinpoint was chosen to assist comparison with Argentina;

** Evidence at $5 \%$ level of significance that annual percentage change is greater than or less than zero.

a reduction in the magnitude of their increasing trends in recent years while mortality cancer in less developed countries still shows a clear ascendant trend 21

Prostate cancer age standardized mortality rates declined significantly $(1.9 \%$ each year) in the last ten years in Córdoba in agreement with Argentinean data (1.6\% each year after 1998). A previous national study in the period 1980-2003 had also reported a similar trend with rates rising up to 1998 and declining from that year 11, similar to that shown by Bouchardy et al. 10 for the period 1977-1996. Other authors, however, had reported a stabilizing of rates in the period 1966-1991 22 . Moreover, the increased rates in the later 1990s in Argentina are consistent with trends in other Latin American countries such as Brazil 23, Chile 24 and Mexico 21.

There are high incident rates of prostate cancer in developed countries, mainly in the USA, where mortality rates from this disease are high, but as in our results, trends are changing 5 . In the last years, prostate cancer age standardized mortality rates declined by $4.17 \%$ each year in the USA, more than double the decline rate estimated for Córdoba and Argentina 22. In the same way, Cayuela et al. 25, in Spain, and Bosetti et al. 26 analyzing cancer mortality in the European Union, found higher rates in the late 1980s which declined thereafter. A recent decline in mortal- ity was particularly observed for prostate cancer (estimated annual percentage change $=-1.0$ from 1994 to 2003) in agreement with our results.

The decline in prostate cancer mortality, mainly in developed countries, might be attributed to screening 27 but there is no complete agreement about its role 28 . Although screening is increasingly available in many high income countries, its impact in reducing mortality is still not very clear. The role of screening and healthcare policy remains controversial since there are uncertainties about the degree of "over-diagnosis" and risk-benefit trade-off 29.

In Argentina, prostate-specific antigen testing was introduced in around the mid 1980s but it never became massive and is not yet included in public health prevention programs. Another important factor to consider and assess in Argentina is the improvement in treatments, namely earlier adoption of transurethral resection of the prostate, as well as hormone (androgen blockage) and radiothe-rapy for patients with locally advanced disease 26 .

The aged-period-cohort models we have used make it possible to estimate the effect of age, cohort and period which are interesting both for understanding the mechanisms of carcinogenesis and for evaluating the impact of newer diagnostic strategies and therapies on cancer mortality 30 . 


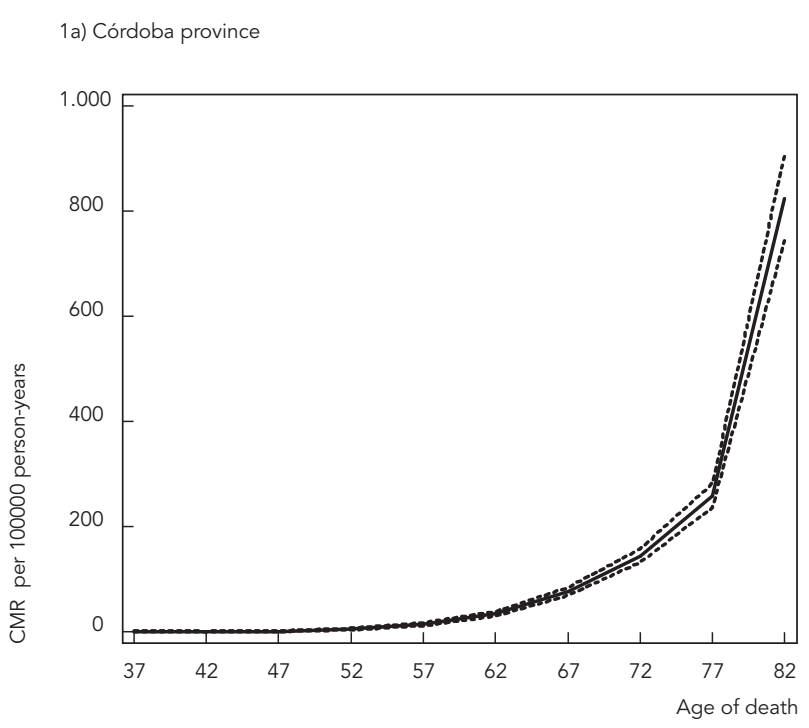

1b) Argentina

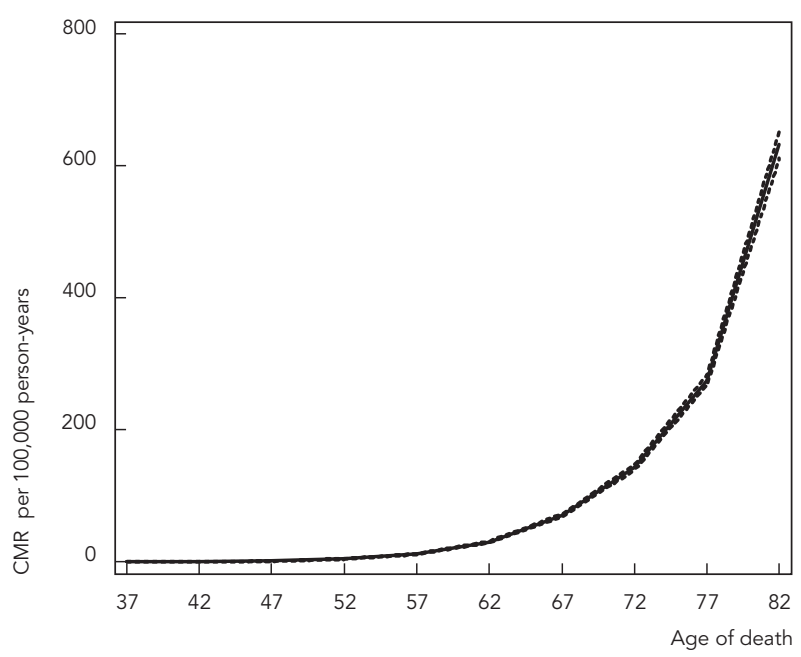

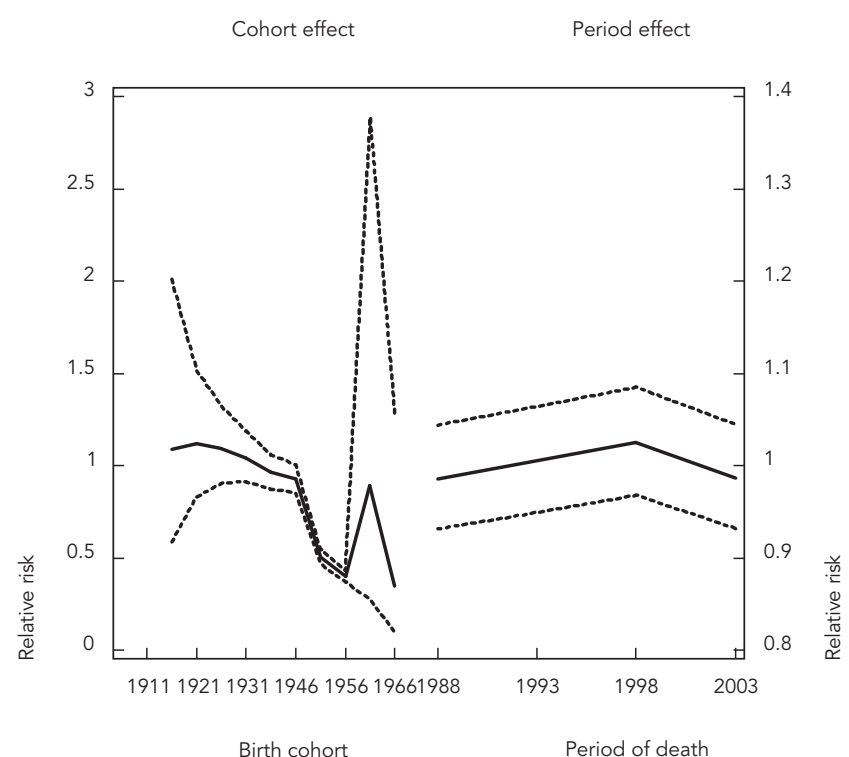

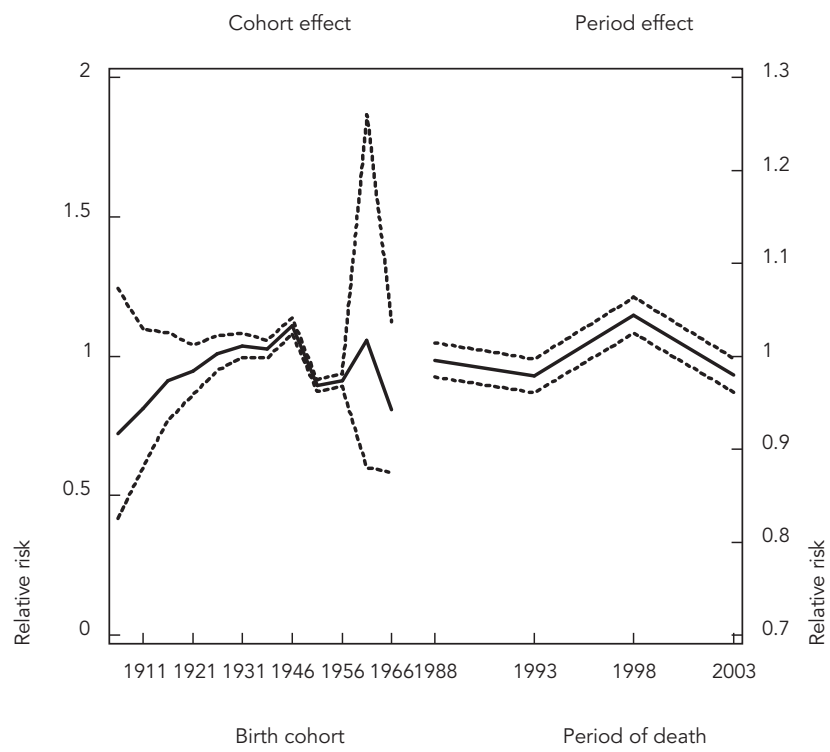

CRM: cancer mortality rate.

Age values are expressed as rates/10-5 person-years. Period of death and cohort of birth effects are expressed in relative terms against their weighted average set to unity.

Solid line: effect estimate; dashed line: $95 \% \mathrm{Cl}$.

Our study showed a significant age effect, which is consistent with the known biology of this pathology. Period of death effect showed a similar magnitude in Córdoba province and Argen- tina. It is interesting to note how period of death RR follows the Argentinean hyper-inflationary crisis ${ }^{31}$. It is likely that in the period following the economic crisis there were more people seek- 
ing medical attention in public health structures than there were resources available. The 1980s had a negative effect on economic growth in Latin America. Conditions of inequity among social groups characterized by very uneven distribution of income were exacerbated with the implementation of stabilization measures that helped to increase poverty and its extreme forms. Furthermore, Buenos Aires, where $38 \%$ of the Argentinean population live, is a target for migrants from rural areas and from other countries such as Bolivia and Peru (where medical care standards are very different from those of Buenos Aires) seeking better conditions of life ${ }^{32}$. Both internal and external migrations to large cities (including Cordoba city) contributed to the growth of the marginalized urban periphery with significant gaps in terms of accessibility to health care services, housing conditions and lifestyle 33 .

The cohort effect did not reach statistical significance in Córdoba province whereas it was present for Argentina for the 1906 to 1921 central year birth cohorts. Argentina in general and Córdoba province in particular, as well as Latin America, show an epidemiological transition with increased life expectancy and reduced mortality rates. This trend may explain the cohort effect we found.

Diet has been long implicated in the development of prostate cancer 5. The Argentinean population traditionally has a high consumption of animal protein and fats obtained mainly from red meat 34 but there are no available studies about temporal trends in dietary intake. An indirect indicator of food consumption included into the Food Balance Sheets, given by FAO (the Food and Agriculture Organization of the United Nations) 35 , reported that bovine meat consumption decreased from 232g/person/day in 1979-1981 to $149 \mathrm{~g}$ in 2001-2003. More recently, between the 1995-97 and 2003-2005 periods, dairy product consumption declined from $605 \mathrm{~g} /$ person/day to $450 \mathrm{~g}$. Both foods have been linked to prostate cancer 5,6, and thus, on the basis of the observed cohort of birth effect found in Córdoba province and Argentina, it is likely that dietary changes operate on younger generations. Although the objective of this study is not to study diet, it is worth mentioning that the Argentinean population has a particular dietary pattern, with a documented profile of cancer risk 36,37 . It therefore could be worthwhile to deepen the study on the relation- ship between diet and prostate cancer trends through further research.

Finally, special consideration must be paid to the underreporting problem of this disease. In fact, the most common difficulty when working with mortality data is underreporting, both from a quantitative (coverage) and qualitative (the correct determination of cause of death) point of view. In Argentina, the coverage level of the Subsystem of Vital Statistics is considered good (more than 95\%) 11.

The analysis of mortality trends is an important tool to monitor cancer control. It remains to be further investigated the relationship between this result with the extent of prostate-specific antigen testing and different treatment modalities in more advanced stages of the disease. However, annual national records of treatments or screening data are not routinely gathered in Argentina, which makes it difficult to observe trends. As such, it will be important to improve cancer registries in our country to closely monitor future trends in both cancer mortality in general and in prostate cancer incidence in particular. Finally, it is important to underline the similar results obtained for Córdoba province and Argentina. Because around $70 \%$ of the Argentinean population is concentrated in three urban areas the study of mortality trends in each of these areas is a good mirror of Argentina as a whole.

\section{Conclusions}

This research presents a new and updated description of temporal trends for prostate cancer mortality rates in Córdoba and Argentina. Recent declines in rates are consistent with that of some developed countries. After reaching a peak in the mid 1990s, prostate cancer age-standardized mortality rates declined significantly in Córdoba and in Argentina by $1.9 \%$ and $1.6 \%$ each year respectively. Moreover, the age-period-cohort model showed a strong age effect, indicating the correlation between aging and prostate cancer mortality. The increased risk in the 1996-2000 period is consistent with the joinpoint results. The birth cohort effect for Córdoba province is similar to the rest of the country with a decreased risk in younger generations, though more markedly in the province, which could be explained by healthier behavioural factors. 


\section{Resumen}

El objetivo de este trabajo fue describir la magnitud, la variación por edad y las tendencias temporales de las tasas de mortalidad por cáncer de próstata en la provincia de Córdoba y en Argentina desde 1986 hasta 2006. Se ajustaron modelos joinpoint y de edad-periodo-cohorte con los datos de mortalidad del Ministerio de Salud de Córdoba y de la Organización Mundial de la Salud. En Argentina las tasas de mortalidad estandarizada por edad aumentaron $1 \%$ y 3,4\% por año desde 1986 a 1992 y desde 1992 a 1998 respectivamente. Fue estimada una tendencia decreciente (-1.6\%) para Argentina desde 1998 y para Córdoba (-1.9\%) desde 1995. Los modelos edad-período-cohorte tanto para Córdoba, como para el país, mostraron un marcado efecto de edad. En el país se encontró un incremento del riesgo en el período 1996-2000, mientras que las cohortes de nacimiento a partir de 1946 mostraron un riesgo decreciente, principalmente para Córdoba. Se encontró una disminución en las tasas de mortalidad por cáncer de próstata en Córdoba y en Argentina, lo cual podría atribuirse a mejoras en los tratamientos en el país.

Neoplasias de la Próstata; Tasa de Mortalidade; Salud del Hombre

\section{Contributors}

C. Niclis coded the mortality data and wrote the final version of the study. S. A. Pou contributed in the production of the article. R. H. Bengió gave signficant contributions in discussing the study. A. R. Osella designed the study and reviewed the manuscript. M. P. Díaz designed the study and reviewed the manuscript.

\section{Acknowledgments}

C. Niclis' research was supported by the Fondo para la Investigación Científica y Técnica (FONCyT) of the Ministerio de Ciencia, Tecnología e Innovación Productiva de la Nación. We are also indebted to the Department of Statistics at the Córdoba Ministry of Health, for kindly allowing us to use the 1986-2006 database.

\section{References}

1. World Health Organization. Annex table 2: deaths by cause, sex and mortality stratum in WHO regions, estimates for 2002. The world health report 2004 - changing history. http://www.who.int/ whr/2004/en (accessed on 28/Nov/2008).

2. World Health Organization. Cancer. Fact sheet $\mathrm{n}$. 297. http://www.who.int/mediacentre/factsheets/ fs297/en/index.html (accessed on 28/Jul/2008).

3. Ferlay J, Bray F, Pisani P, Parkin DM. GLOBOCAN 2002: cancer incidence, mortality and prevalence worldwide. Lyon: IARC Press; 2004. (IARC Cancerbase no. 5 , version 2.0).
4. Ministerio de Salud de la Nación. Agrupamiento de causas de mortalidad por división político territorial de residencia, edad y sexo: República Argentina, año 2006. Buenos Aires: Ministerio de Salud de la Nación; 2006. (Boletín del Programa Nacional de Estadísticas de Salud, 120).

5. World Cancer Research Fund/American Institute for Cancer Research. Cancers. In: World Cancer Research Fund/American Institute for Cancer Research, editors. Food, nutrition, physical activity, and the prevention of cancer. A global perspective. Washington DC: American Institute for Cancer Research; 2007. p. 244-321. 
6. Grönberg H. Prostate cancer epidemiology. Lancet 2003; 361:859-64.

7. Robbins SL, Cotran RS, Kumar V, Collins T. Neoplasias. In: Robbins SL, Cotran RS, Kumar V, Collins T, editors. Patología estructural y funcional. 6th Ed. México DF: McGraw-Hill Interamericana; 2000. p. 277-348.

8. Casal ER, Majdalani MP. Recomendaciones divergentes en el diagnóstico precoz del cáncer de próstata. Medicina (B Aires) 2003; 63:77-81.

9. Díaz MP, Osella AR, Aballay LR, Muñoz SE, Lantieri MJ, Butinof M, et al. Cancer incidence pattern in Córdoba, Argentina. Eur J Cancer Prev 2009; 18:259-66.

10. Bouchardy C, Fioretta G, Rapiti E, Verkooijen HM, Rapin CH, Schmidlin F, et al. Recent trends in prostate cancer mortality show a continuous decrease in several countries. Int J Cancer 2008; 123:421-9.

11. Loria D, Abriata MG, Rosso S. Atlas of cancer mortality trends. Argentina, 1980-2001. Ministerio de Salud, Presidencia de la Nación. http://www.asarca. org.ar (accessed on 17/Feb/2009).

12. Gann PH. Interpreting recent trends in prostate cancer incidence and mortality. Epidemiology 1997; 8:117-20.

13. World Health Organization. International statistical classification of diseases, 10th revision. $2^{\text {nd }} \mathrm{Ed}$. Geneva: World Health Organization; 2005.

14. Doll R, Smith PG. Comparison between registries: age-standardized rates. In: Waterhouse JAH, Muir CS, Shanmugaratnam K, Powell J, Peacham D, Whelan S, editors. Cancer incidence in five continents. v. IV. Lyon: International Agency for Research on Cancer; 1982. p. 671-5. (IARC Scientific Publication, 42).

15. Kim HJ, Fay MP, Feuer EJ, Midthune DN. Permutation test for joinpoint regression with application to cancer rates. Stat Med 2000; 19:335-51.

16. Clayton D, Schifflers E. Models for temporal variation in cancer rates. Age-period and age-cohort models. Stat Med 1987; 6:449-67.

17. Carstensen B. Age-period-cohort models for the Lexis diagram. Stat Med 2007; 26:3018-45.

18. Sankaranarayanan R, Swaminathan R, Black RJ. Global variations in cancer suvrival. Cancer 1996; 78:2461-4.

19. Collin S, Martin R, Metcalfe C, Gunnell D, Albertsen P, Neal D, et al. Prostate-cancer mortality in the USA and UK in 1975-2004: an ecological study. Lancet Oncol 2008; 9:445-52.

20. Decarli A, La Vecchia C. Cancer mortality in Italy, 1992. Tumori 1996; 82:511-5.

21. Salmerón-Castro J, Franco-Marina F, SalazarMartínez E, Lazcano-Ponce E. Epidemiologic panorama of cancer mortality in the Mexican Institute of Social Security: 1991-1995. Salud Pública Méx 1997; 39:266-73.

22. Muñoz SE, Chatenoud L, La Vecchia C, Negri E, Levi F. Trends in cancer mortality in Argentina, 196691. Eur J Cancer Prev 1998; 7:37-44.

23. Chatenoud L, Bertuccio P, Bosetti C, Levi F, Curado MP, Malvezzi M, et al. Trends in cancer mortality in Brazil, 1980-2004. Eur J Cancer Prev 2010;19:79-86.
24. Vives A, Valdivia G, Marshall G. Cambios recientes en la mortalidad por cáncer de próstata en Chile: estudio de tendencias en el período 1955-2001. Rev Med Chil 2004; 132: 579-87.

25. Cayuela A, Rodríguez-Domínguez S, Martín VE, Candau BR. Recent changes in prostate cancer mortality in Spain. Trends analysis from 1991 to 2005. Actas Urol Esp 2008; 32:184-9.

26. Bosetti C, Bertuccio P, Levi F, Lucchini F, Negri E, La Vecchia C. Cancer mortality in the European Union, 1970-2003, with a joinpoint analysis. Ann Oncol 2008; 19:631-40.

27. Hankey BF, Feuer EJ, Clegg LX, et al. Cancer surveillance series: interpreting trends in prostate cancer - part I: evidence of the effects of screening in recent prostate cancer incidence, mortality, and survival rates. J Natl Cancer Inst 1999; 91:1017-24.

28. Oliver SE, May MT, Gunnell D. International trends in prostate-cancer mortality in the "PSA ERA". Int J Cancer 2001; 92: 893-8.

29. Fornara P, Jurczok A. PSA related screening of prostate cancer. Panic or improvement? Aktuelle Urol 2004; 35:43-8.

30. Levi F, La Vecchia C. Age, cohort and period effects on large bowel cancer incidence. Eur J Cancer Prev 2002; 11:515-17.

31. Aguirre P. How the very poor survive: the impact of hyper-inflationary crisis on low income urban households in Buenos Aires, Argentina. GeoJournal 1994; 34:295-304.

32. Peña M, Bacallao J. Obesity and its economic, sociocultural and environmental determinants. In: Pan American Health Organization, editor. Obesity and poverty: a new public health challenge. Washington DC: Pan American Health Organization; 2000

33. Velázquez G, Gómez Lende S. Dinámica migratoria: coyuntura y estructura en la Argentina de fines del XX. Amérique Latine Histoire et Mémoire. Les Cahiers ALHIM, 2004 [on line] index432. html. http://alhim.revues.org/ (accessed on 27/ May/2009).

34. Britos S. Diseño de la canasta básica de alimentos de las áreas metropolitana, NOA, NEA, Cuyo y Sur Informe para el sistema de información, monitoreo y evaluación de programas sociales. Buenos Aires: Ministerio de Desarrollo Social; 2000.

35. Food and Agriculture Organization of the United Nations. FAO food balance sheets. http://www.fao. org/statistics/faostat/foodsecurity/ (accessed on 24/Feb/2009).

36. Navarro A, Osella AR, Muñoz SE, Lantieri MJ, Fabro EA, Eynard AR. Fatty acids, fibers and colorectal cancer risk in Córdoba, Argentina. J Epidemiol Biostat 1998; 3:415-22.

37. Matos E, Brandani A. Review on meat consumption and cancer in South America. Mutat Res 2002; 506-507:243-9.

Submitted on 22/Aug/2009

Final versión resubmitted on 30/Mar/2010 Approved on 17/Aug/2010 